\title{
OTIMIZANDO RESTAURAÇÕES COM RESINA COMPOSTA EM DENTES ANTERIORES
}

Thiago Vinícius Sehn SLAVIERO, Priscilla do Monte Ribeiro BUSATO, Rosana Aparecida dos SANTOS, Sávio BRANDELERO JUNIOR

A comprovada eficácia dos sistemas adesivos para esmalte/dentina e os progressos cada vez mais marcantes no campo das resinas compostas, permitem a realização de procedimentos restauradores de forma mais segura, rápida, agradável e conservadora do ponto de vista estético. Com o objetivo de simplificar a realização das restaurações adesivas diretas auxiliando na reconstrução da face palatina, o uso da guia de silicona tem se tornado um método bastante prático e eficiente. O objetivo deste trabalho é apresentar um relato de caso clínico, de um paciente com necessidades estéticas nos dentes anteriores, entre elas, restaurações insatisfatórias de classes IV e a necessidade de reabilitações anatômica e estética dos incisivos laterais superiores. Foram removidas as restaurações insatisfatórias para que posteriormente fossem realizadas as restaurações desses dentes e a reanatomização dos incisivos laterais superiores utilizando-se resinas compostas Opallis. Tais necessidades foram solucionadas com o auxílio da guia de silicona. Pode se concluir que os dentistas têm que reunir os novos materiais e a tecnologia com os conceitos funcionais tradicionais para terem êxito (MCINTYRE, 2000), e que a guia de silicona facilita e possibilita a confecção de restaurações o mais semelhantes ao natural possível, imperceptíveis visualmente e resistentes mecanicamente.

Palavras-chave: Cárie dentária; Restauração dentária permanente; Estética. 